The Government Uses Motion Pictures*

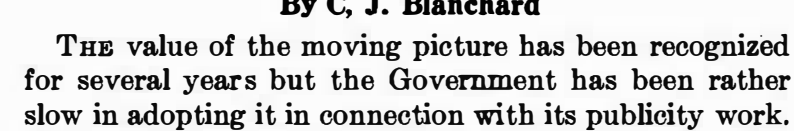

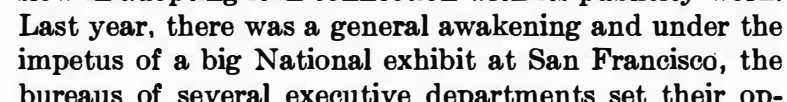

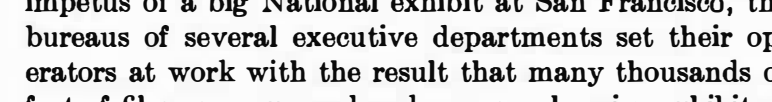

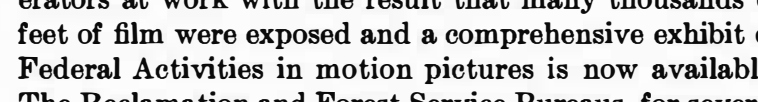

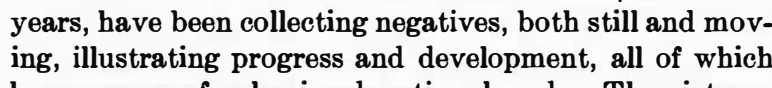

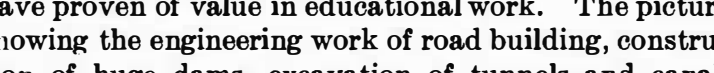

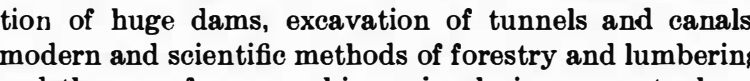

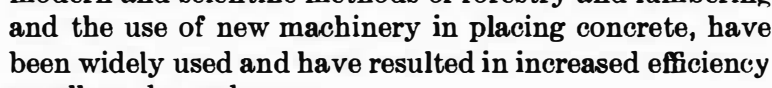

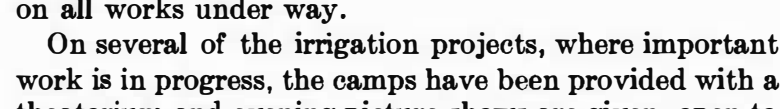
employees and their families. The small admisission

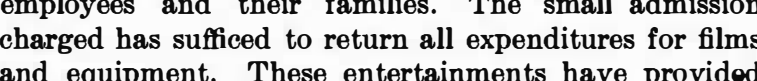

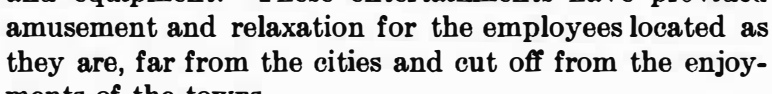

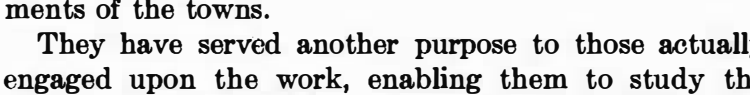

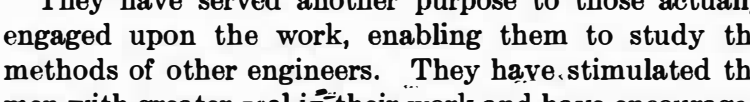

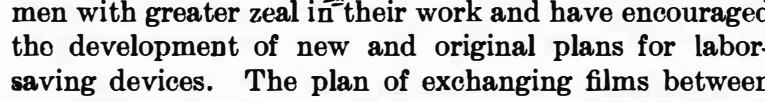

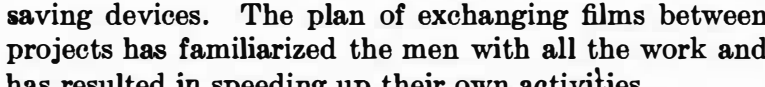

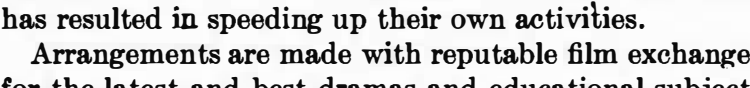

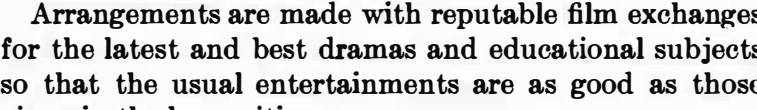
Const

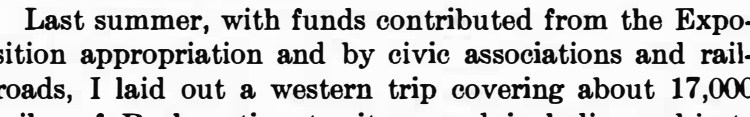

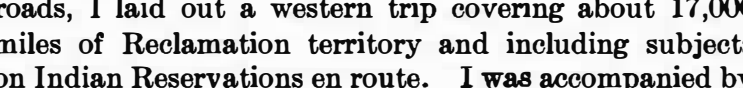
our oficiail photograpapher, Mr. H.T. T. Cowling, with a tull

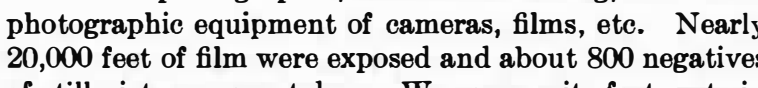

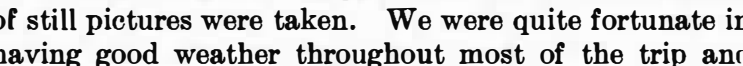

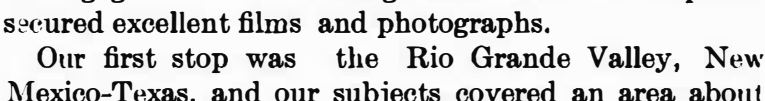

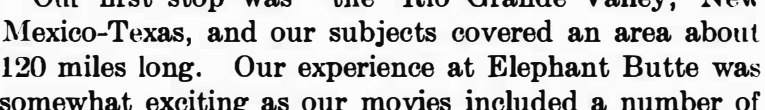

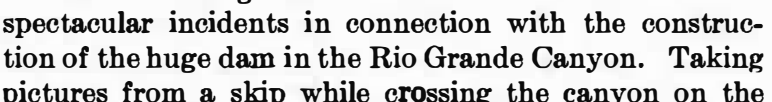

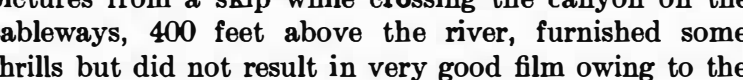
aying of the car and perhaps also to the nervousness

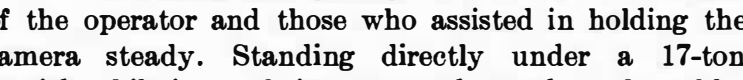

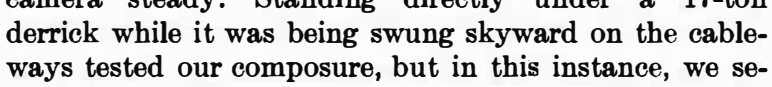

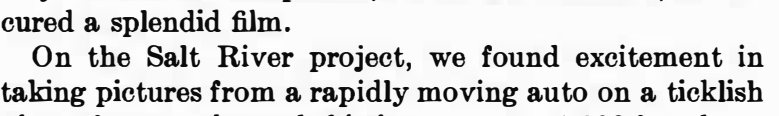

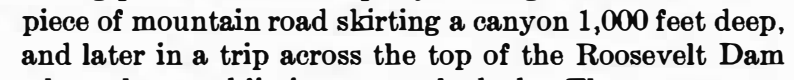

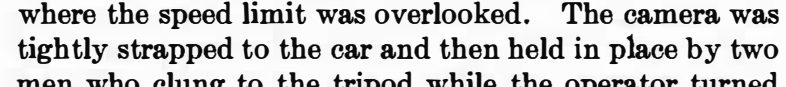

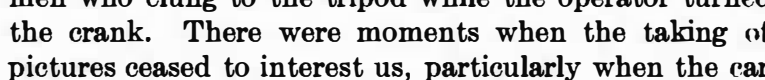

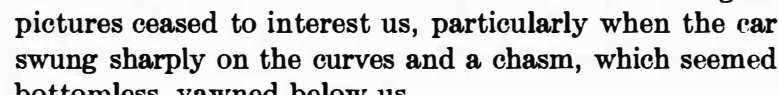

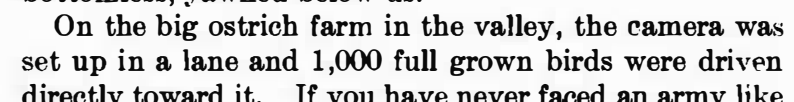

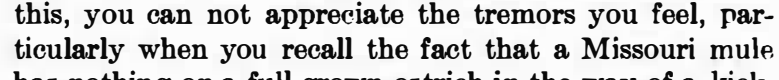

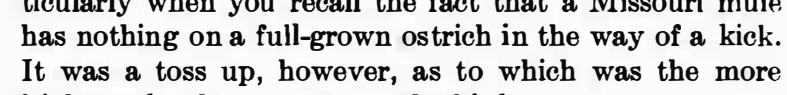
At Yuma, on the Fourth of Jull, with the thermometer

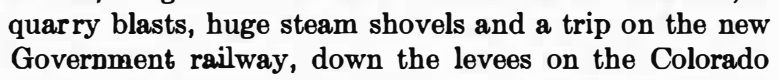

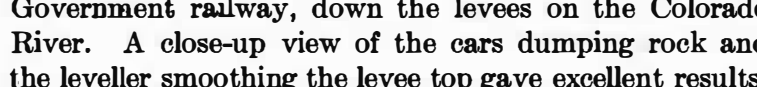

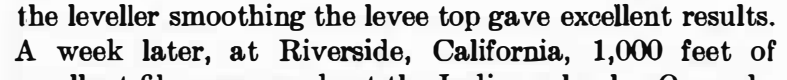

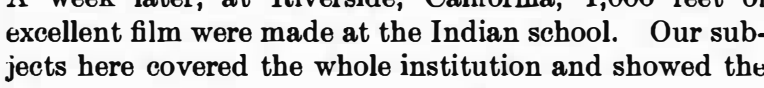

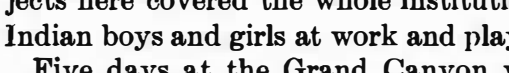
Five days at the Grand Canyon were productive of

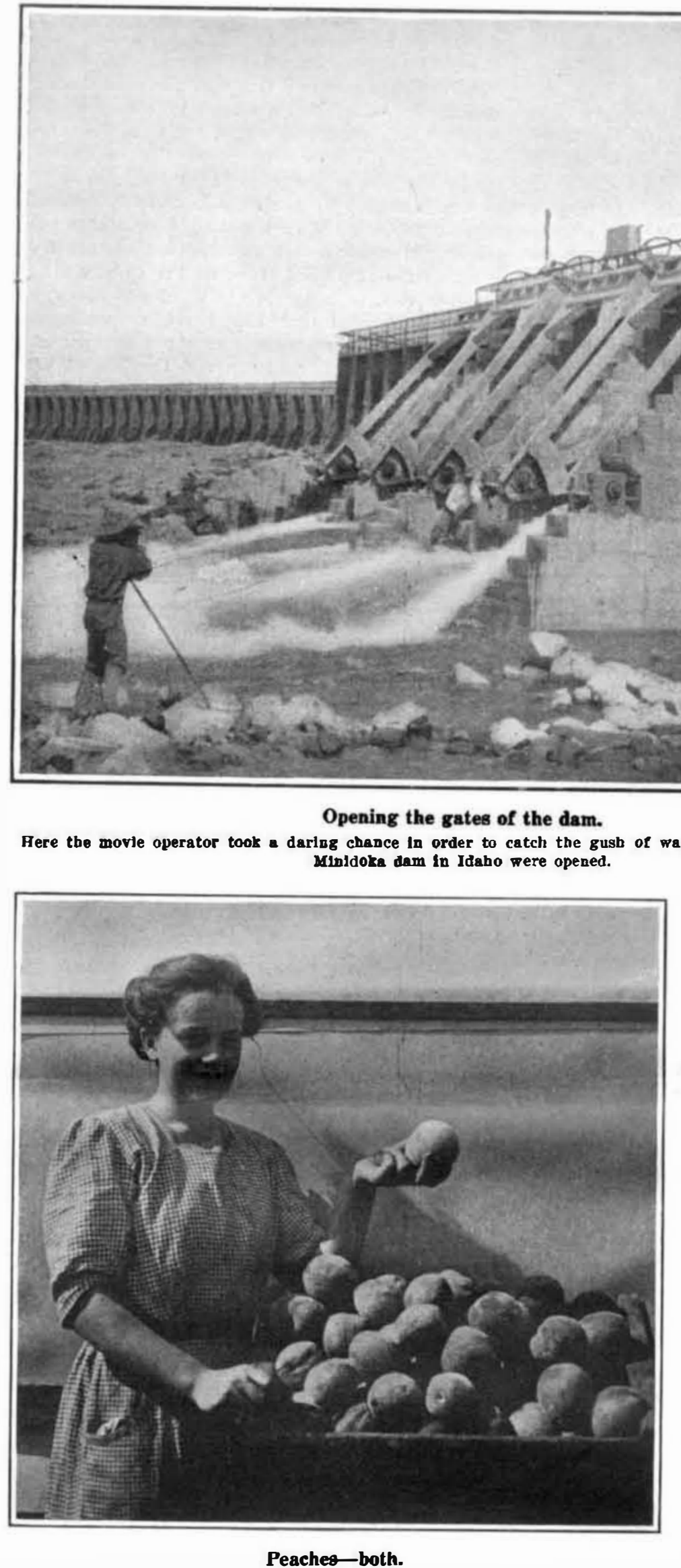

Peachee-both

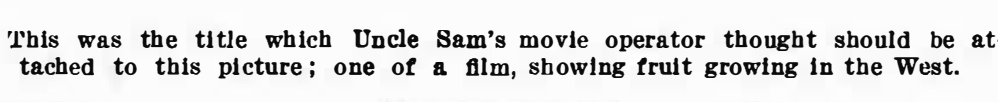

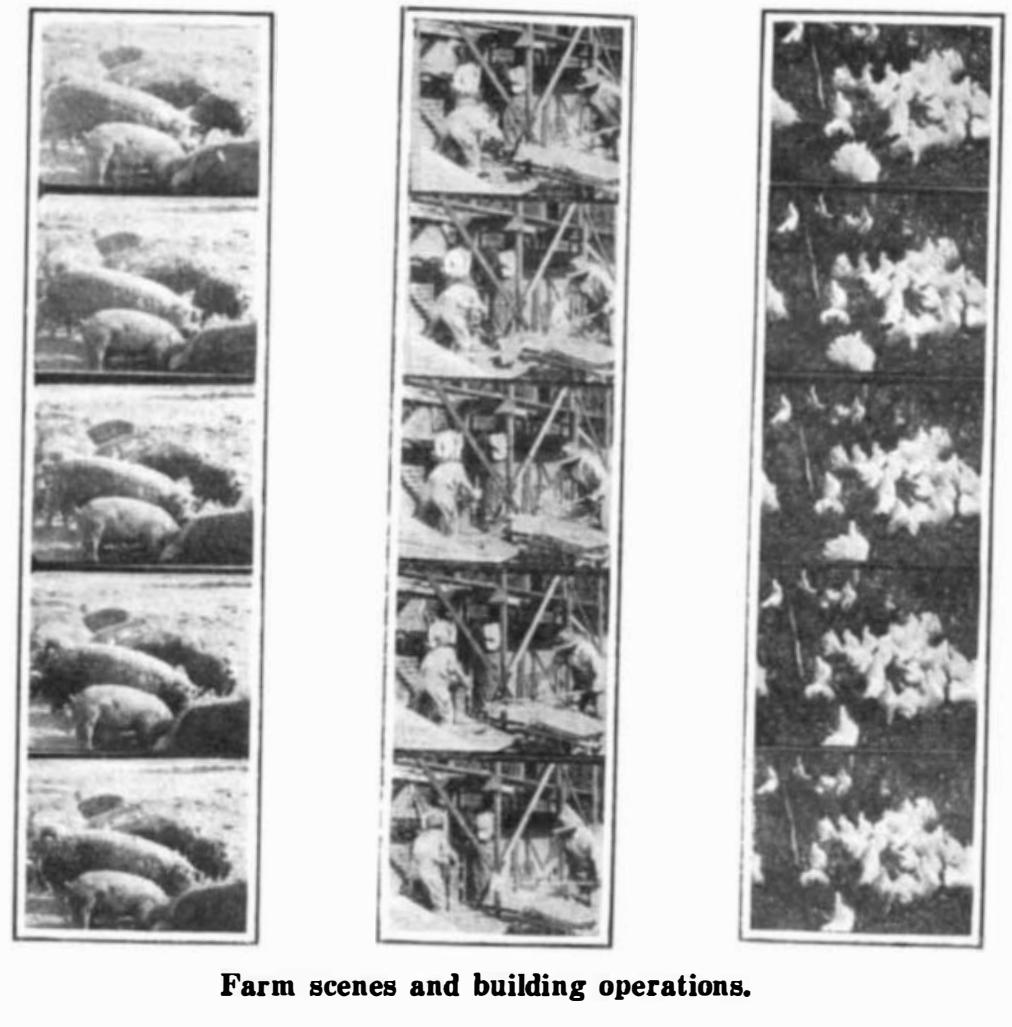

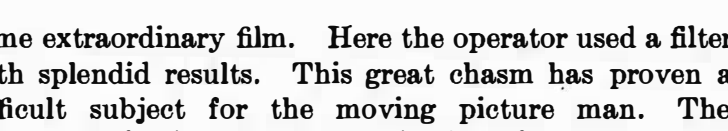
dificicult subject for the moving pieture man. The
Canyon, which is more than a mile deep, is allayss partly

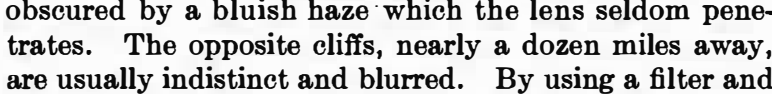
clifs and their delicate and intricate carving were sharply re-
vealded, whilie, at the same time, the towering pinnacles
and The Colorado in flood offered a fine subject for the

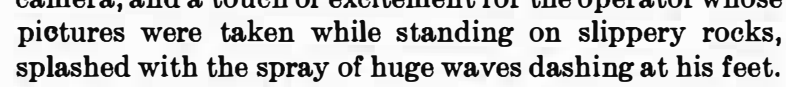
splashed with the spray of huge waves dashing a this feet.
We unilized $a$ number of In Nevada, we were so fortunate as to be on hand when
the last tucketet of concrete was placed in the Lahontan

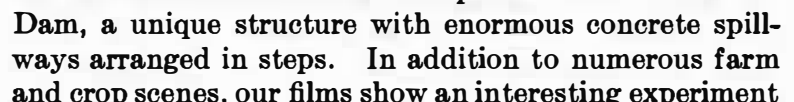
in co-operation. Nand leveld ten acres of sage brush desert tor o r a new
and

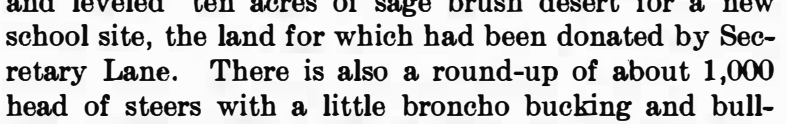
In Idaho, on the Minidoka as rojuecect, our subjects were
varied. Standing on a boulder in Snake River imme-

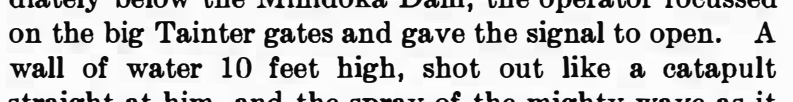
straight at him, and the spray of the mighty wave as it
dashbed aaginst the rocks drenched him to the slin.

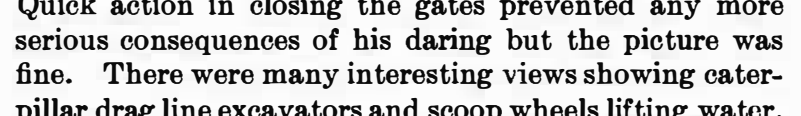
On the Boise project, a number of exposures were made
from the top of Arrowrock Dam, which is to be the highabove the river, the camera was set to show the entive proeess of placing concrete. An entirely new and ing an especially fine subject for a picture. From a large
mixing plant on the side of the canyon, two huge buckets

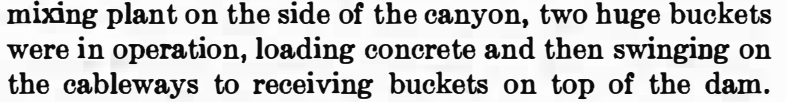
the cablevays to receiving buckets on top of the daa
The receiving buckets sususended from the cableways. took their loads and discharged them through pipes
various sections of the dam. The pipes were movab

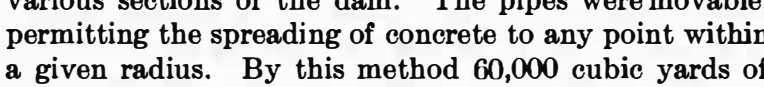

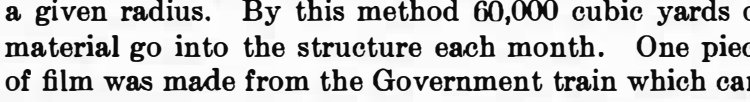
ried us through the big camp and into the steep wall
canyon. All the views were impressive as this greer

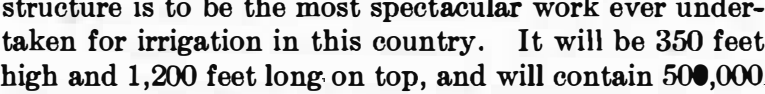

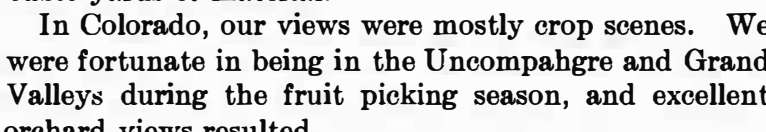
In Montanan the seenes on the Lower Yellowstone and
Huntley projects were of roposs. The harvesting of suger beets furnished an exoellent subject. Encouraged by our suceesses on other projects, when
we reached the Shoshone projecet in Wyoming, we deter-r-

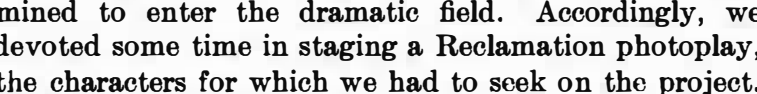

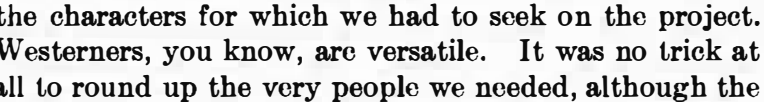

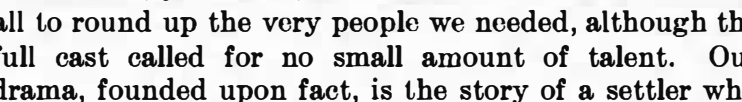

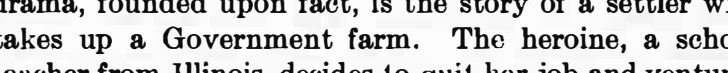

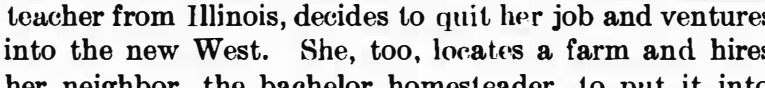

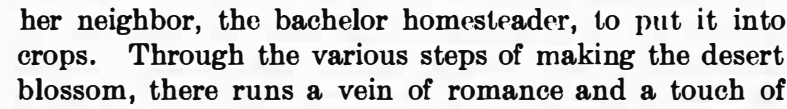
blossom, there runs a vein of romance and a touch of
tragedd for the heroine's shome is burned down during her absence. The betrothal comes when the young farmer
tries to comfort the heroine in her loss. The film, in

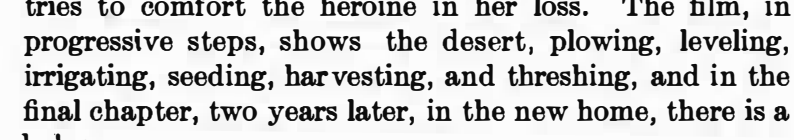
baby.
These films are to be shown in daily lectures at the
Panamazaracific Exposition and should serve to acquaint

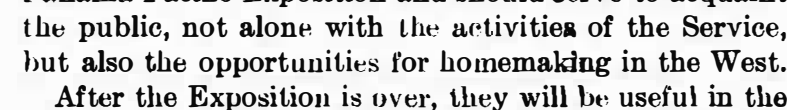
hectures which have become an important unuction of the 
The War and Navy Departments are entitled to special mention in connection with the utilization of the moving picture. Orders are about to be placed for more than 100 projecting machines which will be installed in numerous forts, in the field and o several battleships. Soldiers and sailors are to enjoy
the same films which to-day are viewed in every city and town in the world, the service to be obtained through the regular exchanges. Films will be used also for educa-
tional purposes in connection with the training and fit ting of the men for their various duties.

Excellent film was obtained last summer by severa bureaus of the Department of Agriculture, by the Bureau
The activities of the Government in Alaska are quite ully portrayed on several thousand feet of film.

The presentation of these films at the Panama-Pacific Exposition, and later, before popular audiences throughout the oountry is bound to make the general publio more familiar with our Government and its many active functions.

\title{
The Therapeutic Uses of Preparations of the Ductless Glands-I*
}

\author{
Notes on Experimental Investigations of Undoubted Future Value
}

By Robert G. Torrey, M.D.

In the recent work in the realm of plysiology there are few efforts which stand out as possibly of striking importance. Some years ago the theory of anaphylaxis was advanced by Poirtier and Richet, and their hypotheses have to a large extent been supported by subsequent investigation. 'The benefit already attained by the practical application of their theories is incalculable. More recently the work in the von Noorden clinie, particularly by kppinger and Hess, holds a wealth of suggestion and has already borne fruit in the clinical feld. Countless investigators are now working on the problems presented by the ductless glands - their interrelationship and the physiological effect of their activity in health and in states of disturbed function. The relationship of the ductless glands to the nervous tone is not as yet well understood. It seentis definitely established that the pancreas produces an internal secretion which the pancreas produces an internal secretion which acts as a sympathetic depressant; that the chrom-
affine system as a whole acts as a sympathetic affine system as a whole acts as a sympathetic
stimulant, or at least as an activator of certain portions of the system; and that the thyroid and hypophysis both in some way inhibit the activity of the pancreas in its nervous effect. This whole subject is so shrouded in doubt, however, that the theoretical side will not be considered here, this paper being limited to a discussion of the therapeutic experimentation which is being at of the therapeutic experimentation which is
tempted with the ductless gland preparations.

Much of this work is pure speculation, much of it doubtless altogether useless, but time and experience will certainly extract some facts which are valuable and which can be shown to rest on a solid foundation. In attempting to put these theories to practical therapeutic use, the broadening of the field of endeavor depends on the practicing physicians. Those who are acquainted with these theories will be on the alert to recognize many interesting conditions which would otherwise many interesting
escape observation.

THE ADRENAL GLAND.

The adrenal gland or suprarenal body is of all the glands the one about which the most accurate information has been acquired. The Isolation of an active principle of a definite chemical nature has made possible experimental work which is more exact than is usual in dealing with animal substances.

The suprarenal body is composed of two portions, morphologically, chemically, and physiologically distinct phologically, chemically, and physiologically distinct. to the nervous system, while the cortex contalns cells to the nervous system, while the cortex contalns cells which stand in relation to certain cells of the sex glands.
It is possible that in administerlng extracts or prepara It is possible that in administering extracts or prepara-
tion of the suprarenal gland we have two distinct tion of the suprarenal gland we have two distinct
effects produced-one the result of a medullary substance which activates or stlmulates the terminals of the sympathetic nerves. Most of the known action of the glandular extract can be attributed to this factor, including vasoconstriction, hyperglycemia or glycosurla (due to action on the sympathetics of the liver), pupi(due to action on the sympathetics of the liver), pupi-
lary reaction, and relasation of the bronchl. Apart from lary reaction, and relaxation of the bronchl. Apart from
this action, which may be directly chemical in nature, this action, which may be directly chemical in nature,
we have to consider the action of the cells of the cortex Animal experimentation is a rather uncertain Index of the physiological effect of adrenalin on the huma being, as the results of its administration vary a great deal in different species; also the effect is subject to wide variation, depending on many factors, such as nerve depression, as by drugs, muscular relaxation, etc. For instance, adrenalin will cause a marked contraction In a vessel which is relaxed or dilated, while if the In a vessel which is relaxed or dilated, while if the
vessel is already in a state of good tone there will be vessel is already in a state of good tone there will be
little or no effect shown. A small dose may produce a result entirely different from that produced by a larger dose.

As is well known, in the human body adrenalin ad ministered intravenously causes a marked but transient rise in blood-pressure due to contraction of the peripheral arteries. It does not, however, constrict the coronary arteries, but probably dilates them. Its effect on the heart depends on the activity of the vagus, and this is an Important factor In determining the extent - Tho Therepoutio osectia of the blood-pressure rise. 'The bronchi are inarkedly tivity are decreased. The mobilization of sugar is increased with a resulting hyperglycemia or glycosuria. Cannon calls the service of the adrenal secretion to the organism an emergency function, increasing the effciency of faitigured muscle and decreasing the clotting time of the blood. Fe also points out that stiong emotional disturbances stimulate the discharge of epine phrin, continued worry leading to exhaustion and insufficiency of the gland.

In therapeutics Its chief employment has been as a local vasoconstrictor, particularly in dealing with the membranes of the nose and throat. Infectlons of membranes of the nose and throat. Injectlons of adrenalin have been found very useful in combating
the vascular relaxation incident to shock, and while Its action in this regard is very brief, it may prevent collapse in emergency. It is of value as a palliative measure in certain asthmatic affections, when an in jection of from three to ten minims of the one-to-one thousand solution either into a vein or deep in a nuscle may terminate an attack almost immediately. While it gives prompt temporary relief in a number of these cases of bronchial asthma and of so-called cardiac asthma, it seems to have no permanent curative effect; but fortunately the susceptlbility to the drug is not lost by repeated use, and increased dosage does not appear to be necessary. In antitoxin rashes, whlch are sometimes of serlous moment, particularly if accompanied by edema of the glottis, it has been shown that an infection of adrenalin may altogether relieve the patient of symptoms within five or ten mlnutes. Here again the effect is not permanent and repeated doses may be necessary. I have seen acute circumscribed edema of the lip and of the tongue practically dlsappear within ten or fifteen mlnutes after the injection appear within ten or fifteen mlnutes after the injection
of ten minims of adrenalin solution Into a vein on the back of the hand.

Adrenalin is recommended in the vomlting of preg nancy. Zuloaga has continued the admlnistration of adrenalin in severe and otherwise uncontrollable vomItlng from the second month of pregnancy to term, starting with ten drops every eight hours and later glving five drops every twelve hours, alternating with calcium. He is enthusiastic regarding thls treatment. Cavazzanl has collected forty-seven cases in which a cure of osteomalacia is claimed to have been effected by systematic adrenalin treatment. He refers partlcularly to the assumption that deficlent functionlng of the adrenals interferes with normal skeletal growth, and discusses the question of etiology of rickets in this connection.

In the preparation termed adrenalin we have to deal with not only the chemical substance adrenalin or epinephrin, the product of the medullary cells, but also with an extract of the cortical cells, the nature and functions of which are totally distinct from those of the tions of which are totally distinct from those of the of life the so-called interrenal body, which corresponds to the cortex of the suprarenal gland in the higher animals, is Indispensable to life, while the adrena representing the medulla of the gland may be removed without fatal results. It is probable that in Addison's disease the destructlon of the cortex is largely responsible for the condition, and also the cortex may be in question in osteomalacia and rickets. In the matter of Influencing growth and development of the skeletal tissues and of the sex glands, the cortex is probably more sues and of the sex glands, the cortex is probably more
important than the chromafine cells of the medulla. Many writers have considered the question of a general myasthenla, distinct from but frequently confused with neurasthenia, which is due to adrenal Insufficiency and which yields to organotherapy (thyroid, pituitary, and adrenal being recommended).

I have noticed patients showing various grades of general myasthenia, low blood-pressure, poor skin clrculation, and slight pains which seemed referred to the heart, who seemed benefited by the dried adrenal gland administered by mouth; also the pituitary gland gland administered by mouth; also the pituitary gland
bas seemed of service; but thyroid must in these cases be tried with great caution and carefully watched for ad effects.

In summarizing our present knowiedge of the use of the adrenal gland as a therapeutic agent, it may be said that certain immediate and direct actions for which the medullary portion is responsible may be granted; on the other hand, there is probably an action due to cortical substances which has an effect on the nutrition of muscle and bone, and in certain diseases, as suggested,. its effect may be sought by gland administration. In Addison's disease, where its use is theo retically Indicated, the reports of suecess with adrenalin are not frequent or convincing.

Adrenalin is generally. sold in one-to-one-thousand solution, which is reliable if fresh. It deteriorates rapidly, particularly if exposed to the light. The average dose is from five to ten minims of this solution in fected well diluted into a vein or deeply into a muscle. The dried gland is also sold and seems to have a certain value when the cortical effect is desired.

The intravenous use of adrenalin is said to be contraindicated in organic heart lesions, nephritis, and arteriosclerosis. In animals it has been shown by Pearce that it is possible by large dosage to produce arterial degeneration, but its use in the ordinary dose subcutaneously has not to my knowledge been shown to be harmful, even when employed frequently and over long perlods, as in cases of asthme. THYBord.

Next to the adrenal, the thyroid is the gland of which we have the most knowledge chemically, though thls knowledge is limited to very narrow boundaries. We know that lodine is a constituent of the gland and that In a measure its physiological activlty corresponds to the amount of absorption of metabolized lodine. Iodine is held In combination with the colloid substance of the gland. Whether this combination forms a definlte chemical substance is not establlshed. Also the effect of this so-called Indothyrine in hyperthyroidism and Graves's disease is not thoroughly understood. Hyperplastic and hypertrophied glands contaln as a rule less iodine than normal glands or colloid goitres. Thls does not mean, however, that less is present in the system, as the lodine content varles roughly wlth the amount of colloid substance, while the symptoms produced Increase as the absorptive power due to the epithelial elements of the gland increases and with the power of taking up and metabolizing lodine, which power of taking up and metabolizing lodine, w

Different disorders due to variations in the gland are attributed to an excess or lack of combined lodine and the excess of uncombined iodine in the system. Thus lodine poisoning bears a certain resemblance to thyroid disease. Iodine which has been found to be beneficial in endemic goitres is distinctly lnfurious in acute goitres of the hypertrophic type, glving many of the symptoms of Graves's dlsease, Including gastric and intestinal derangements, tremor, emaciation and muscular weakness. The administration of lodine subcutaneously or by absorption from the skin, will markedly raise the iodine content of the thyroid gland Administered by mouth its effect seems to be less marked.

Histologically, the normal thyroid gland is composed of acini lined with a laver of epithelial cells. The acini goitre the acini are greatly enlarged, the cells flattened or atrophied, and the colloid greatly in excess.

In cases with a thyroid givlng marked Graves's symptoms, we are apt to find a proliferation of the epithelial cells, and, Instead of a single layer of lining cells, a thyroid adenoma with papillomatous outgrowths into the acini and proliferation of the lining layer. This overgrowth later tends toward atrophy. Thus in a patient with enlargement of the thyroid, even with exophthalmos and marked tremor, we may have to deal with a case of hypothyroidism, as truly as though we had a subject of myxedema or a cretin in question.

It ls worthy of note that the hypertrophy of the gland may come on acutely and probably as a result of one 